\title{
SPECTROPHOTOMETRIC DETERMINATION OF CEFPIROME IN PHARMACEUTICAL PREPARATION
}

\section{DILIP M CHAFLE*}

Department of Chemistry, Faculty of Science, Taywade College, Koradi, Nagpur, India. Email: dmchafle@gmail.com

Received: 16 April 2020, Revised and Accepted: 27 May 2020

\begin{abstract}
Objective: A simple, sensitive and precise visible spectrophotometric method has been proposed for the determination of cefpirome (CFM) in pure and oral injectable dosage form.

Methods: A spectrophotometric method is based on the formation of stable red color product by oxidation of drugs by ferric nitrate and subsequent complexation with 1,10 - phenanthroline with maximum absorption at $515 \mathrm{~nm}$.

Result: The red color complex was formed between Fe (II) and 1, 10 - phenanthroline after reduction of Fe (III) to Fe (II) in the presence of CFM drug. The phosphoric acid solution was used only for quenching the complex formation reaction. Several parameters such as the maximum wavelength of absorption, the volume of reagents, sequence of addition and effect of temperature and time of heating were optimized to achieve high sensitivity, stability and reproducible results. Under the optimum conditions, linear relationship with good correlation coefficient (0.994) was found over the concentration range from 0.20 to $6.00 \mu \mathrm{g} / \mathrm{mL}$ with a molar extinction coefficient $7.7813 \times 10^{4} \mathrm{~L} / \mathrm{mol} / \mathrm{cm}$, limit of detection 0.2026 and limit of quantification $0.6141 \mu \mathrm{g} / \mathrm{mL}$, respectively.
\end{abstract}

Conclusion: The proposed method was evaluated statistically for linearity, accuracy, and precision in terms of standard deviation, percentage recovery, percentage error and relative standard deviation. The proposed method can be applied for the routine estimation of CFM in the laboratory.

Keywords: Cefpirome, Spectrophotometric, 1, 10-Phenanthroline, Ferric Nitrate.

(C) 2020 The Authors. Published by Innovare Academic Sciences Pvt Ltd. This is an open access article under the CC BY license (http://creativecommons. org/licenses/by/4. 0/) DOI: http://dx.doi.org/10.22159/ajpcr.2020.v13i9.38457

\section{INTRODUCTION}

Cephalosporins are of first, second, third, fourth, and fifthgeneration types. Cefpirome (CFM) belongs to the fourth generation cephalosporins. It is a broad-spectrum oral antibiotic available in vial form in the pharmaceutical market. It shows antimicrobial and bactericidal characteristics. It binds to plasma proteins and disrupts the synthesis of the main cell wall polymer, peptidoglycan. It penetrates the cell wall of bacteria extremely rapidly and binds to the target enzymes with high affinity. It is sensitive at low concentration against an extremely broad spectrum of Gram-negative pathogens such as Citrobacter spp., E. coli, Salmonella spp., Shigella spp., Klebsiella spp., and Enterobacter spp. and Gram-positive pathogens such as Staphylococcus aureus, Streptococcus sanguis, Streptococcus viridans, and Streptococcus pneumoniae. Therefore, it is recommended in the treatment of complicated respiratory tract infection, skin and soft tissue infections and bacteremia [1-5].

CFM is official in Martindale the extra pharmacopeia [6]. It is chemically [[(6R - 7R) - 7 - [2 - (2 - aminothiazol - 4 - yl) 2 - methoxyiminoacetyl amino] - 3 - $(6,7$ - dihydro $-5 \mathrm{H}$ - cyclopenta $[\beta]$ pyridinium - 1azabicyclo [4.2.0] - oct - 2 ene -2 carboxylate monosulfate. (Fig. 1).

The literature survey reveals that Micellar Electro Kinetic Chromatography (MEKC) $[7,8]$ was described in the quantification of CFM in human plasma as well. It was introduced to determine the partitioning behavior of various cephalosporins in microemulsions. High-performance liquid chromatography (HPLC) technique was applied using ultrafiltration [9] to determine CFM in serum. Some physical aspects such as stability study [10], dissociation constants of CFM were studied by HPLC and potentiometric method [11] and metal drug interaction study by reverse-phase high-performance liquid chromatography (RP-HPLC) [12]. The quantitative determination of CFM in raw material and pharmaceutical dosage was reported by microbiological assay method [13], liquid chromatography (LC), and ultraviolet-visible (UV)-spectrophotometry [14], UPLC [15] and HPLC [16]. Very few spectrophotometric methods for CFM and other cephalosporins are reported using 3-methyl-2-benzothiazolinone hydrazone hydrochloride (MBTH) [17] and ferricyanide [18] as chromogenic reagents.

Spectrophotometric methods are so popular for their sensitivity and simplicity. Henceforth, these methods have offered considerable attention for the quantitative determination of pharmaceutical compounds. This method shows good sensitivity and specificity and permits discrimination in the face of the broadband interference arising from non-specific matrix absorption. However, some reported spectrophotometric methods are sensitive at comparatively higher concentration of drug, some of it requires specific structural requirement such as intact amino thiazole ring and alkoxy imino substituent while other have maximum absorption toward either end of the visible spectrum.

The aim of the present work is to develop an analytical method which will be simple, sensitive, rapid and sensible at the mid of the visible spectra even at low concentration of drug in pharmaceutical preparations. The proposed method is based on the ability of CFM to form a stable red-colored product with 1, 10 - phenanthroline after heating with ferric nitrate.

\section{METHODS}

\section{Instrument}

An equiptronic EQ 882 visible spectrophotometer (India) with a bandwidth of $1.0 \mathrm{~nm}$, equipped with $1.0 \mathrm{~cm}$ matched quartz cells were used for all spectral measurements. 
Reagents

All the chemicals used were of analytical grade and all solutions were prepared in double-distilled water. Oral pharmaceutical preparation of CFM in the form of vials, namely, Bacirom injection (Aristo Pharmaceutical Pvt. Ltd., Bhopal, India), Forgen injection (Alkem Laboratories Ltd., Ankaleshwar, India) and Cefrom injection (Aventis Pharma Ltd., Mumbai, India) was procured from the local market.

Ferric nitrate $(0.0033 \mathrm{~mol} / \mathrm{L}), 1,10$ - phenanthroline $(0.01 \mathrm{~mol} / \mathrm{L})$ and phosphoric acid $(0.2 \mathrm{~mol} / \mathrm{L})$ were prepared by dissolving the appropriate amount in $100 \mathrm{~mL}$ water.

Preparation of standard stock solution $(40 \mu \mathrm{g} / \mathrm{mL})$ - standard stock solution of CFM $(40 \mu \mathrm{g} / \mathrm{mL})$ was prepared by dissolving $100 \mathrm{mg}$ of pure CFM drug in $100 \mathrm{~mL}$ water. It further dilutes to get a working standard stock solution of $40 \mu \mathrm{g} / \mathrm{mL}$.

Preparation of sample solution of drug $(40 \mu \mathrm{g} / \mathrm{mL})$ - an accurate amount of sample powder from vial of Bacirom, Forgen, and Cefrom injections were weighed equivalent to $100 \mathrm{mg}$ and dissolved in 100 $\mathrm{mL}$ water and filter the solution with Whatman filter paper. Finally, a sample solution of $40 \mu \mathrm{g} / \mathrm{mL}$ was obtained by appropriate dilution.

\section{General recommended procedure}

An aliquot ranging from 0.2 to $4.0 \mathrm{~mL}$ of working standard solution of CFM was transferred into $25 \mathrm{~mL}$ volumetric flasks. A volume of $2.5 \mathrm{~mL}$ of ferric nitrate solution, $4.0 \mathrm{~mL}$ of 1,10 - phenanthroline solution was added sequentially. The flasks were heated on a circulating water bath at $60 \pm 2^{\circ} \mathrm{C}$ for $15 \mathrm{~min}$. Then, $3.0 \mathrm{ml}$ of phosphoric acid solution was added and cooled to room temperature. Finally, the volume was made to $25 \mathrm{~mL}$ by water. Similarly, a blank was prepared without drug. The resulted redcolored solution was scanned for absorbance at $515 \mathrm{~nm}$ on Equiptronic EQ 882 spectrophotometer against reagent blank. A standard calibration curve was prepared by plotting absorbance against the concentration of CFM. Similarly, sample solutions were analyzed. The concentration of CFM in the sample solution was determined from the calibration curve.

\section{RESULTS AND DISCUSSION}

\section{Reaction mechanism}

The cephalosporin antibiotics are susceptible to redox reactions. CFM reduces $\mathrm{Fe}$ (III) to $\mathrm{Fe}$ (II) in an aqueous medium at elevated temperature $60 \pm 2{ }^{\circ} \mathrm{C}$. Fe (II) then forms in situ a red color complex with complexing agent 1, 10 phenanthroline in the 1:3 molar ratios. The formation of complex between Fe (II) and 1, 10 phenanthroline can be quenched instantly in the presence of phosphate ions, provided by phosphoric acid. The possible mechanism of complex formation can be shown as follows

$$
\begin{gathered}
\mathrm{Fe}_{a q}^{3+}+\mathrm{CFM}_{a q} \rightarrow \mathrm{Fe}_{a q}^{2+} \\
\mathrm{Fe}_{a q}^{2+}+3(1,10-\text { Phenanthroline }) \rightarrow\left[\mathrm{Fe}^{I I}(1,10-\text { Phenanthroline })_{3}\right]
\end{gathered}
$$

The resultant red color complex was Ferroin which shows the maximum wavelength of absorbance $\left(\lambda_{\max }\right)$ at $515 \mathrm{~nm}$ in the visible spectrum. This colored complex formed was stable for more than 24 hours.

\section{Optimization of the reaction conditions}

Maximum wavelength of absorption $\left(\lambda_{\max }\right)$

An aliquot of $4.0 \mathrm{~mL}$ of working standard solution of CFM, $2.5 \mathrm{~mL}$ of ferric nitrate solution and $4.0 \mathrm{~mL}$ of phenanthroline solution was transferred to a $25 \mathrm{~mL}$ flask. The reaction mixture was heated on a circulating water bath for 15 minutes at $60 \pm 2{ }^{\circ} \mathrm{C}$. Immediately, 3.0 $\mathrm{ml}$ of phosphoric acid was added and mixture was cooled to room temperature. Finally, the volume was made to $25 \mathrm{~mL}$ by water. Similarly, blank was prepared without drug. The resulted red-colored solution was scanned over the visible range of spectrum of Equiptronic EQ 882 spectrophotometer against reagent blank. The visible spectra obtained are as shown in Fig. 2.
Effect of reagent concentration

The optimum concentration of reagents was estimated by keeping the concentration of CFM and other reagents constant, except one of the reagents under consideration was varied. The volume required for the development of maximum color intensity was investigated from subsequent absorbance measurement at $\lambda$. The results showed that the absorbance of the colored species increased with the increase in the volume of ferric nitrate and phenanthroline. However, absorbance was found to be decreased with an increase in volume of phosphoric acid. The maximum volume of ferric nitrate, phenanthroline and phosphoric acid found were $2.5 \mathrm{~mL}, 4.0 \mathrm{~mL}$ and $3.0 \mathrm{~mL}$, respectively (Fig. 3). Hence, an excess volume of reagents has no effect on the determination of drug.

\section{Effect of temperature and time of heating}

The optimum temperature was investigated by recording color intensity at an increasing temperature above room temperature. The maximum and constant absorbance was obtained at $60 \pm 2^{\circ} \mathrm{C}$ temperature. Similarly, optimum reaction time was investigated by quenching the reaction intermittently on a heating water bath at different time

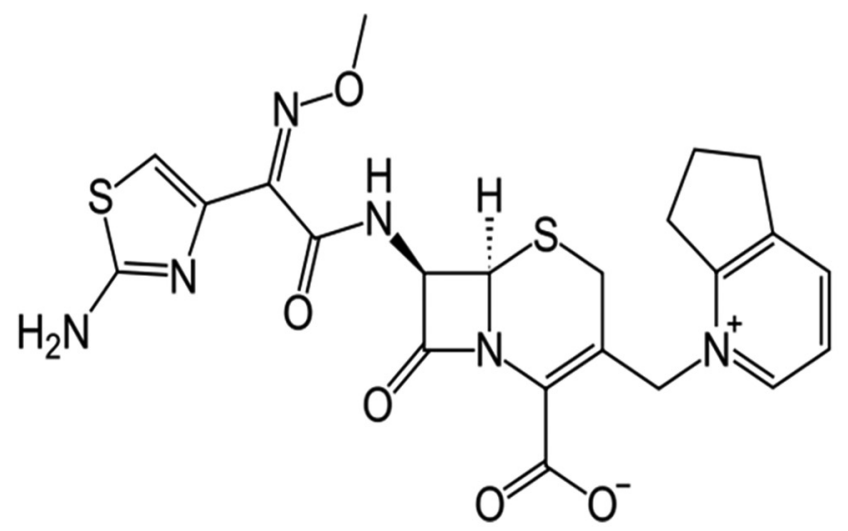

Fig. 1: The chemical structure of cefpirome

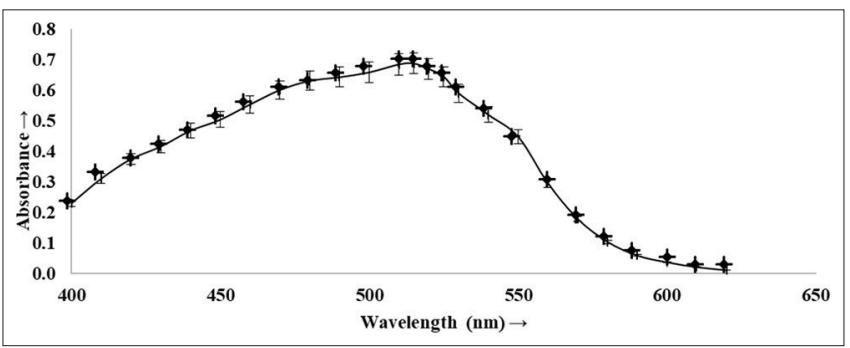

Fig. 2: Absorption spectra of red-colored complex with $(6 \mu \mathrm{g} / \mathrm{mL})$ of cefpirome between $\mathrm{Fe}$ (II) and phenanthroline $\left(1.0 \times 10^{-2} \mathrm{~mol} / \mathrm{L}\right)$ in the visible range $(n=1)$



Fig. 3: Effect of concentration of reagents on complex formation with $(2,4$, and $6 \mu \mathrm{g} / \mathrm{mL})$ cefpirome, ferric nitrate $\left(3.3 \times 10^{-3} \mathrm{~mol} / \mathrm{L}\right)$, phenanthroline $\left(1.0 \times 10^{-2} \mathrm{~mol} / \mathrm{L}\right)$, and phosphoric acid $(0.2 \mathrm{~mol} / \mathrm{L})(\mathrm{n}=3)$ 
intervals. The maximum and constant color intensity were obtained after $15 \mathrm{~min}$. Heating more than $15 \mathrm{~min}$ above $60^{\circ} \mathrm{C}$ is of no use because the absorbance above this condition remains constant (Figs. 4 and 5).

\section{Method of validation}

Linearity

A standard calibration curve was constructed by plotting the absorbance against the concentration of CFM. The statistical parameters were given in the regression equation calculated from the calibration curve $\mathrm{Y}=\mathrm{a}+$ $\mathrm{mX}$, where $\mathrm{Y}$ is the absorbance, $\mathrm{X}$ is a concentration of CFM in $\mu \mathrm{g} / \mathrm{mL}, \mathrm{m}$ is slope and a is intercept on y-axis. The linearity of calibration graph was proved by a high value of correlation coefficient $\left(R^{2}\right)$ and small value of $y$-intercept of the regression equation. The linearity range of calibration curve was found to be limiting in the range $0.2-6.0 \mu \mathrm{g} / \mathrm{mL}$ concentration of CFM (Fig. 6). The molar absorptivity and Sandell's sensitivity of the resulting red color complex were calculated and found to be $7.7813 \times$ $10^{4} \mathrm{~L} / \mathrm{mol} / \mathrm{cm}$ and $0.003469 \mu \mathrm{g} / \mathrm{cm}^{2}$, respectively (Table 1 ). High value of molar absorptivity indicates that the method is sensitive.

Sensitivity

The limits of detection (LOD) and limits of quantification (LOQ) were calculate for the proposed method using the following equation

$$
L O D=\frac{3.3 \times \delta}{m} \text { and } L O Q=\frac{10 \times \delta}{m}
$$

Where $\delta$ is the standard deviation from the intercept of ten replicate determinations values of the reagent blank and $m$ is the slope of the Beer's calibration curve.

According to these equations, the limits of detection (LOD) and limits of quantification (LOQ) were found to be 0.2026 and $0.6141 \mu \mathrm{g} / \mathrm{mL}$.

\section{Application to pharmaceutical preparation}

The proposed method has been successfully applied for the determination of CFM in pharmaceutical preparations. A suitable aliquot of sample solutions of Bacirom, Forgen, and Cefrom injection was taken in linearity range and similarly treated as described in general recommended procedure. The accuracy, precision and repeatability of

Table 1: The analytical data and spectral characteristics in the determination of cefpirome by the proposed method

\begin{tabular}{ll}
\hline Parameters & Result \\
\hline Maximum wavelength of absorbance $\lambda_{\max }(\mathrm{nm})$ & 515 \\
Color of the complex & Red \\
Beer's law limit $(\mu \mathrm{g} / \mathrm{mL})$ & $0.2-6.0$ \\
Molar absorptivity $(\mathrm{L} / \mathrm{mol} / \mathrm{cm}) \times 10^{4}$ & 7.7813 \\
Sandell's sensitivity $\left(\mu \mathrm{g} / \mathrm{cm}^{2}\right)$ & 0.003469 \\
Regression equation* & \\
Intercept (a) & 0.234 \\
Slope $(\mathrm{m})$ & 0.127 \\
Standard deviation of intercept $(\mathrm{Sa})$ & 0.0078 \\
Regression coefficient $\left(\mathrm{R}^{2}\right)$ & 0.994 \\
LOD $(\mu \mathrm{g} / \mathrm{mL})$ & 0.2026 \\
LOQ $(\mu \mathrm{g} / \mathrm{mL})$ & 0.6141 \\
\hline$* \mathrm{Y})$
\end{tabular}

$* \mathrm{Y}=\mathrm{a}+\mathrm{mX}$, where $\mathrm{X}$ is the concentration of CFM in $\mu \mathrm{g} / \mathrm{mL}, \mathrm{Y}$ is the absorbance units, LOD is limits of detection and LOQ is limits of quantification the proposed method were tested by means of recovery study for five replicate determinations for label claims in the samples. The percentage recovery of drug in sample was above $99.9 \%$, the percentage error ranging from 0.016 to 0.123 , the standard deviation (SD) was between \pm 0.1396 and \pm 1.1284 , and relative standard deviation (RSD) was from 0.06 to 0.11 (Table 2). It shows that the proposed method has good accuracy, precision and repeatability. The result of the estimation of

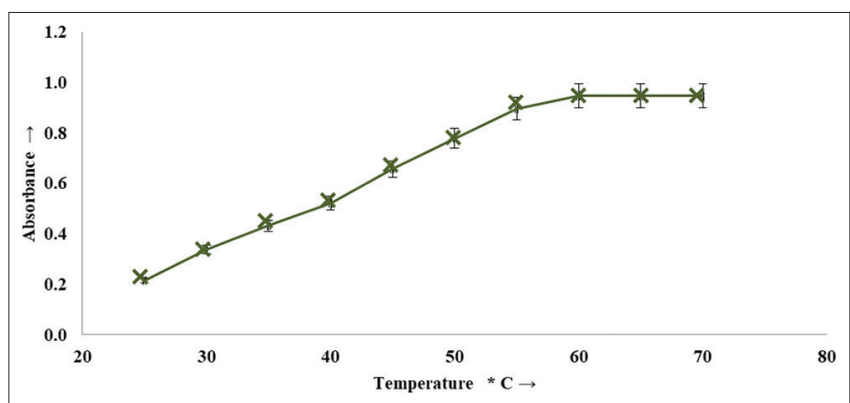

Fig. 4: Effect of temperature on complex formation reaction with $(2,4$, and $6 \mu \mathrm{g} / \mathrm{mL})$ cefpirome, ferric nitrate $\left(3.3 \times 10^{-3} \mathrm{~mol} / \mathrm{L}\right)$, phenanthroline $\left(1.0 \times 10^{-2} \mathrm{~mol} / \mathrm{L}\right)$, and phosphoric acid $(0.2 \mathrm{~mol} / \mathrm{L})(\mathrm{n}=3)$

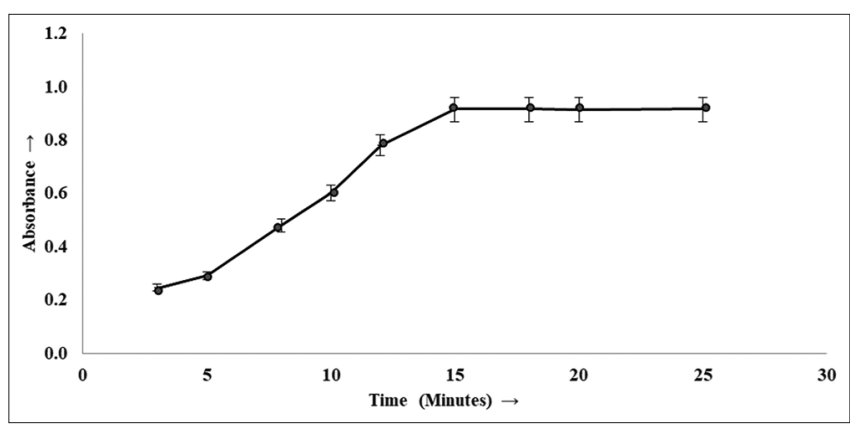

Fig. 5: Effect of heating time on complex formation reaction with $(2,4$, and $6 \mu \mathrm{g} / \mathrm{mL})$ cefpirome, ferric nitrate $\left(3.3 \times 10^{-3} \mathrm{~mol} / \mathrm{L}\right)$, phenanthroline $\left(1.0 \times 10^{-2} \mathrm{~mol} / \mathrm{L}\right)$, and phosphoric acid $(0.2 \mathrm{~mol} / \mathrm{L})(\mathrm{n}=3)$

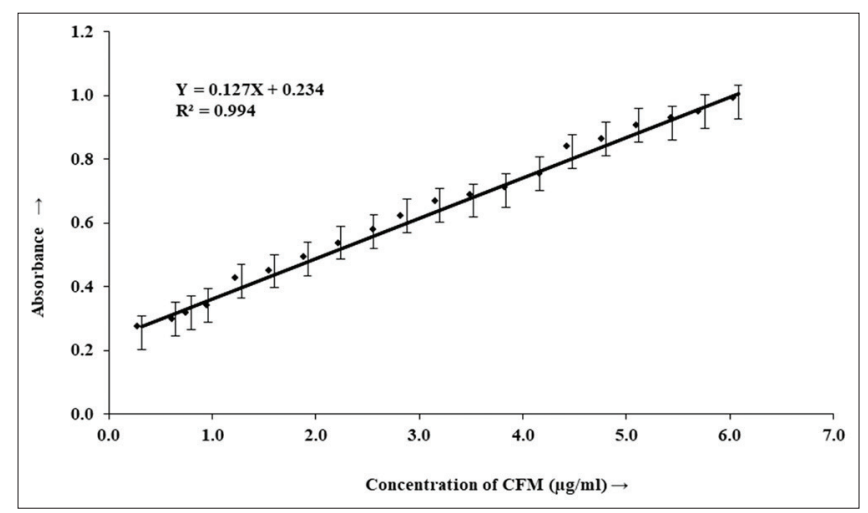

Fig. 6: Beer's calibration curve of cefpirome at optimized condition

Table 2: Result of recovery study, accuracy and precision for the determination of cefpirome in pharmaceutical preparations using the proposed method

\begin{tabular}{lllllll}
\hline Brand name of preparation & Make & Labeled claim $\mathbf{( m g )}$ & Amount found $(\mathbf{m g})$ & Mean recovery $\mathbf{0} \pm$ SD $^{*}$ & Error $\%$ & RSD* \\
\hline Bacirom injection & Aristo & 250 & 249.960 & $99.984 \pm 0.1396$ & 0.016 & 0.0559 \\
Forgen injection & Alkem & 1000 & 998.776 & $99.877 \pm 1.1840$ & 0.123 & 0.1130 \\
Cefrom injection & Aventis & 1000 & 999.364 & $99.936 \pm 0.7391$ & 0.064 & 0.0740 \\
\hline
\end{tabular}

*For five determinations, SD - Standard deviation, RSD - Relative standard deviation 
drug in the sample was found to be in good agreement with label claim which indicates the absence of interference of excipients.

\section{CONCLUSION}

This paper describes the application of a simple visible spectrophotometric technique using oxidation-reduction reaction between drug and metal ion for the quantification of CFM in bulk and pharmaceutical preparations. The proposed method is simple, sensitive, with reasonable precision and accuracy in the visible range. It is further found that the percentage recovery is good enough so that the proposed method is free from the excipient interference. It is applicable to detect CFM even at a very low concentration level. Therefore, the proposed method can be recommended for the routine estimation of CFM in bulk as well as pharmaceutical preparations.

\section{ACKNOWLEDGMENT}

The author is thankful to the Principal of Taywade College, Koradi, for providing infrastructure facilities to carry this research work.

\section{AUTHOR'S CONTRIBUTIONS}

The author Dr. Dilip M. Chafle has himself generated the idea and carried out the experiment. He himself interpreted the data and drafted the manuscript. He has also checked spelling, plagiarism, and finally submitted the manuscript.

\section{CONFLICTS OF INTEREST}

The author confirms that this article content has no conflicts of interest.

\section{AUTHOR'S FUNDING}

The author is grateful to the University Grants Commission, Western Region, Pune, India, for financial assistance to carry research work under a minor research project.

\section{REFERENCES}

1. Tumah HN. In vitro activity of cefepime and cefpirome compared to other third generation cephem antibiotics against gram-negative nosocomial pathogens. Pharmazie 2004;59:854-8.

2. Roos JF, Lipman J, Kirkpatrick CM. Population pharmacokinetics and pharmacodynamics of cefpirome in critically ill patients against gramnegative Bacteria. Intensive Care Med 2007;33:781-8.

3. Hollenstein U, Brunner M, Mayer BX, Delacher S, Erovic B, Eichler HG, et al. Target site concentrations after continuous infusion and bolus injection of cefpirome to healthy volunteers. Clin Pharmacol
Ther 2000;67:229-36.

4. Joukhadar C, Klein N, Mayer BX, Kreischitz N, Dellekarth G, Palkovits $\mathrm{P}$, et al. Plasma and tissue pharmacokinetics of cefpirome in patients with sepsis. Crit Care Med 2002;30:1478-82.

5. Ali MD, Shamim MD, Alam S, Ali S, Ahmad S, Ansari S. Drug utilization based ADRs detection of antibiotics prescribed for LRTI in a tertiary care teaching hospital, New Delhi. Int J Pharm Pharm Sci 2018;10:7-14.

6. Reynolds JE. Martindale: The Extra Pharmacopoeia. 30 ${ }^{\text {th }} \mathrm{ed}$. London: The Pharmaceutical Press; 1993. p.133.

7. Mayer BX, Hollenstein U, Brunner M, Eichler HG, Muller M, Micellar electro kinetic chromatography for the analysis of cefpirome in microdialysis and plasma samples obtained in vivo from human volunteers. Electrophoresis 2000;21:1558-64.

8. Mrestani Y, El-Mokdad N, Ruttinger HH, Neubert R. Characterization of partitioning behavior of cephalosporins using microemulsion and micellar electro kinetic chromatography. Electrophoresis 2005;19:2895-9.

9. Breilh D, Lavallee C, Fratia A, Ducint D, Cony-Makhoul P. Saux MC. Determination of cefepime and cefpirome in human serum by HPLC using an ultrafiltration for antibiotics serum extraction. J Chromatgr B Biomed Sci Appl 1999;734:121-7.

10. Rasool MD, Gopinath H, Asma SK, Marey P, Rao KS. Stability studies of cefpirome sulphate I.V. with metronidazole I.V. admixture. J Chem Pharm Sci 2012;5:165-72.

11. Evagelou V, Tsantili-Kakoulidoli A, Koupparis M. Determination of the dissociation constant of the cephalosporins cefepime and cefpirome using UV-spectrophotometry and pH-potentiometry. J Pharm Biomed Anal 2003;31:1119-28.

12. Sqeed, A, Sultana N, Nawaz M. A RP-HPLC method for the assay of cefpirome and its application in drug metal interaction studies. Pak J Pharm Sci 2006;19:38-43.

13. Oppe TP, Menegola J, Schapoval EE. Microbiological assay for the determination of cefpirome in raw material and injectable preparation. Drug Anal Res 2018;2:29-35.

14. Oppe TP, Menegola J, Schapoval EE. Development and validation of UV-spectrophotometry and liquid chromatography methods for determination of cefpirome in raw material and pharmaceutical dosage. Drug Anal Res 2019;3:42-50.

15. Pavuluri S, Sddiraju S. UPLC method development and validation for the determination of cefpirome sulphate in pharmaceutical dosage form. Int J Pharm 2016;6:168-73

16. Nawaz M, Saeed AM, Sultana N. Simultaneous determination of cefpirome, cefaclor, ceftezidine and cephadrine in pharmaceutical formulations by reverse phase HPLC. Acta Chromatogr 2011;23:205-13.

17. Rao JV, Kumar DA, Rao DM, Nayana T, Silpa D. Spectrophotometric assay of cefpirome sulphate. Ind J Pharm Sci 2005;67:747-8.

18. Hosny MM. Development of simple green spectrophotometric method for determination of cefoperazone sodium and cefepime hydrochloride in bulk, pharmaceutical dosage forms and human urine. Asian J Pharm Clin Res 2014;7:145-50. 